\title{
The use of social media in volcano science communication: challenges and opportunities
}

\begin{abstract}
"Do you understand how cool it is that Twitter has given everyone who wants it direct access to a scientist? Like, no matter who you are, if you have a question about something, you can now literally just go to any scientist and ask them. That is the coolest fucking thing ever."
\end{abstract}

- Erin Biba @erinbiba

\section{INTRODUCTION}

Volcanoes have always captured people's imagination, featuring in our religions, oral and written traditions, art and news. The earliest depiction of a volcano is thought to be the 36,000 year old spray-shape signs in the Chauvet-Pont d'Arc Cave in Ardèche, France [Nomade et al. 2016] or the mural excavated at the Neolithic Çatalhöyük site (Central Anatolia, Turkey) dated to 6600 BCE [Schmitt et al. 2014]. Both are coincident with local volcanic activity and so are thought to record those eruptions. Volcanoes feature in myths, legends and oral histories [Cashman and Cronin 2008]. For example, in Northern Tonga the legends describing the exploits of Sekatoa may record 3000 years of volcanic activity [Taylor 1995] and Hawaiian oral tradition records 400 years of eruptions at Kìlauea [Swanson 2008]. The Greek and Roman literature have written records of Mediterranean volcanic activity dating back to 700 B.C. The eruptive history of Etna between 696 and 425 B.C. can be interpreted from Thucydides' explicit testimony [Stothers and Rampino 1983] and Pliny's letters to Tacitus in A.D. 106 are some of the most famous written descriptions of historic volcanism, detailing the A.D. 79 eruption of Vesuvius and the destruction of Pompeii [Sullivan 1968]. The German manuscript of The Voyage of Saint Brendan contains the earliest known sketch of a volcano, and dates to the 15th Century. Volcanoes have been a fascination for landscape artists in the Western World since the 16th Century. Vesuvius became a focus for writers and scientists in the long 19th century, its sublime power appealing to the romantic movement [Pyle 2017].

It was the 1883 eruption of Krakatau, Indonesia, which first received the attention of the global mass media. Thanks to the newly laid telegraphic lines, newspapers were able to report on this catastrophic eruption only a day after it occurred [Dörries 2003]. The telegraph reports of Krakatau heralded a new era in interest in global catastrophic events and coincided with an increasing interest in the natural world. At the turn of the 20th century, the eruptions of Mt Soufrière, St Vincent and Mt Pelée, Martinique both saw significant global news coverage. They also drew the attention of volcanologists, such as Dr Edmund Otis Hovey (American Museum of Natural History), Sir John S. Flett (University of Edinburgh and Geological Survey of Britain) and Dr Tempest Anderson (Royal Society Commission and the Yorkshire Philosophical Society), who visited in the aftermath of the catastrophic eruptions in 1902, publishing on their findings. They also returned with some of the first photos of various volcanic phenomena including pyroclastic density currents (nuées ardentes) which delighted the attendees to their many subsequent public lectures. Anderson was particularly known for his public talks using 'magic lantern slides' giving Victorian Society an incredible opportunity to see images of volcanic eruptions, landscapes and the people impacted by them [York Museums and Gallery Trust 2017].

Today, this fascination with volcanology continues. Newspaper column inches continue to carry news of eruptions around the world and to report on new research on volcanoes. Volcanology features in films, documentaries and TV news programmes. Volcanologists continue to give talks and interactive events to public






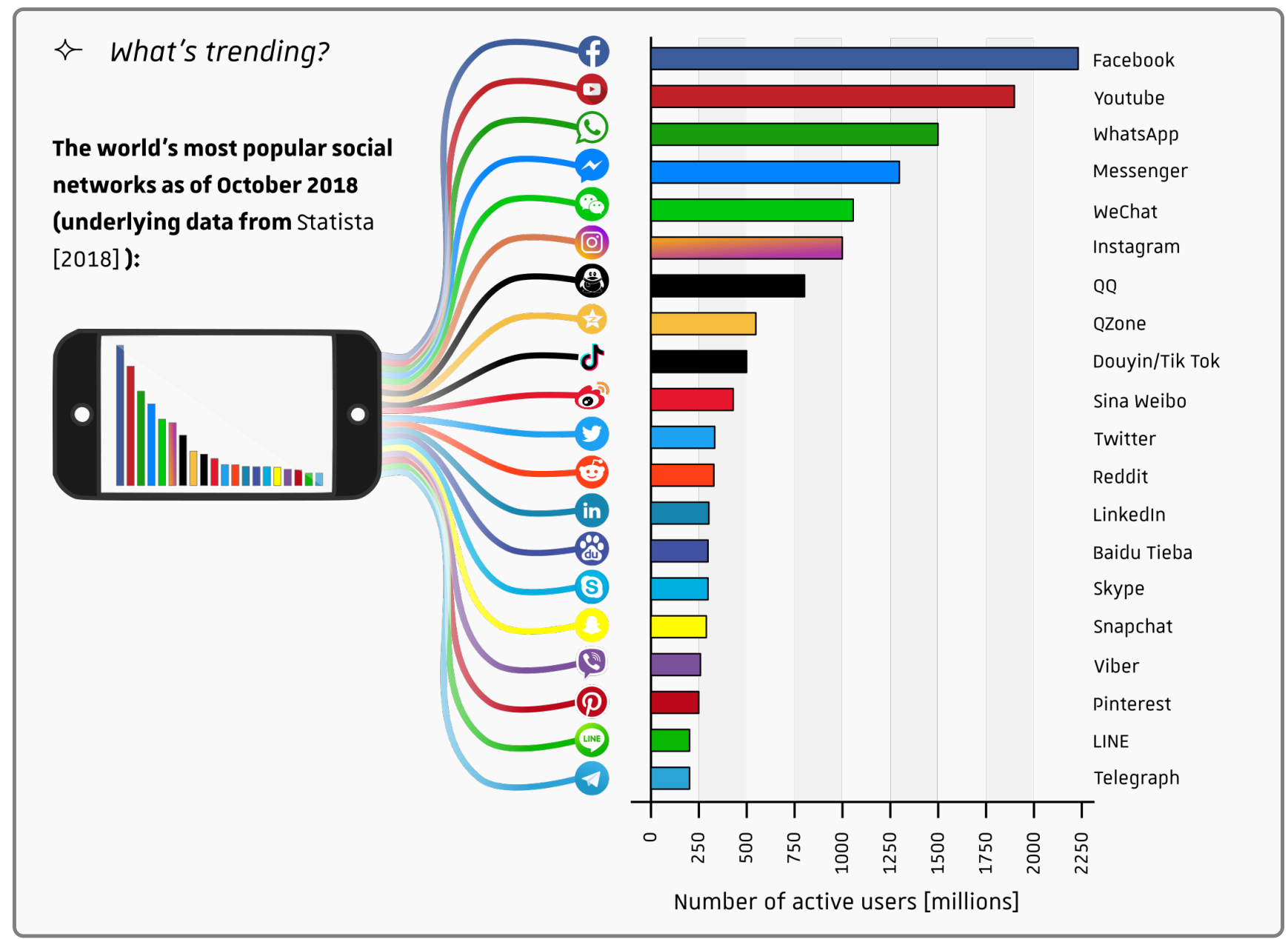

audiences at universities, museums and science festivals. Most recently, social media gives members of the public unprecedented access to volcanologists, volcano observatories and institutions and amateur volcanologists. Social media are interactive websites and applications where users generate and share content for social networking. Content can be text, photographs, videos, links to other websites or data. Users can be anonymous or not, can be individuals or organisations, can create content or just follow others who do, can share original content or reshare content generated by others, and can 'like' or boost content shared by other users. There are over 3 billion internet users using social media sites, and these numbers are expected to grow [Kemp 2018]. The most famous social media site, Facebook, has 2234 million users [Statista 2018]. YouTube, WhatsApp, Facebook Messenger, WeChat and Instagram all have over a billion users each. Social media can be a powerful tool for volcanologists to communicate their science, particularly during a volcanic crisis. The rapidity with which news can be posted and then disseminated through social media can allow for quickly disseminating information, sharing official sources of information, seeing rumours forming in real time and addressing them, and having a two-way conversation (answering questions) with the public. But it can also allow for in- correct information to be spread just as rapidly.

This new instantaneous, global interaction between the media, public, volcanologists and Disaster Risk Reduction (DRR) agencies is a growing field for research. Here we discuss this growing field, some challenges that research needs to address and the role Volcanica can take in disseminating this work.

\section{COMMUNICATION DURING A VOLCANIC CRISIS}

During a volcanic crisis, effective communication between the institution responsible for monitoring the volcano, local government, civil defense authorities, the media and ultimately the public is essential to ensuring safe management of the crisis. A breakdown in communication between these groups of people can lead to unsafe behaviours during a volcanic eruption (e.g. returning to an evacuation zone), mistrust in authorities (e.g. during and after the 1999 forced evacuation at Tungurahua; Stone et al. [2014] and Tobin and Whiteford [2002]), widespread anxiety (e.g. Guadeloupe; Fiske [1984]) and devastation to the local economy even when there is no volcanic threat (e.g. early 1980s at Mammoth Mountain; Blakeslee [2011] and Hill et al. [2017]). At its very worst, it can lead to a volcanic disaster. In 


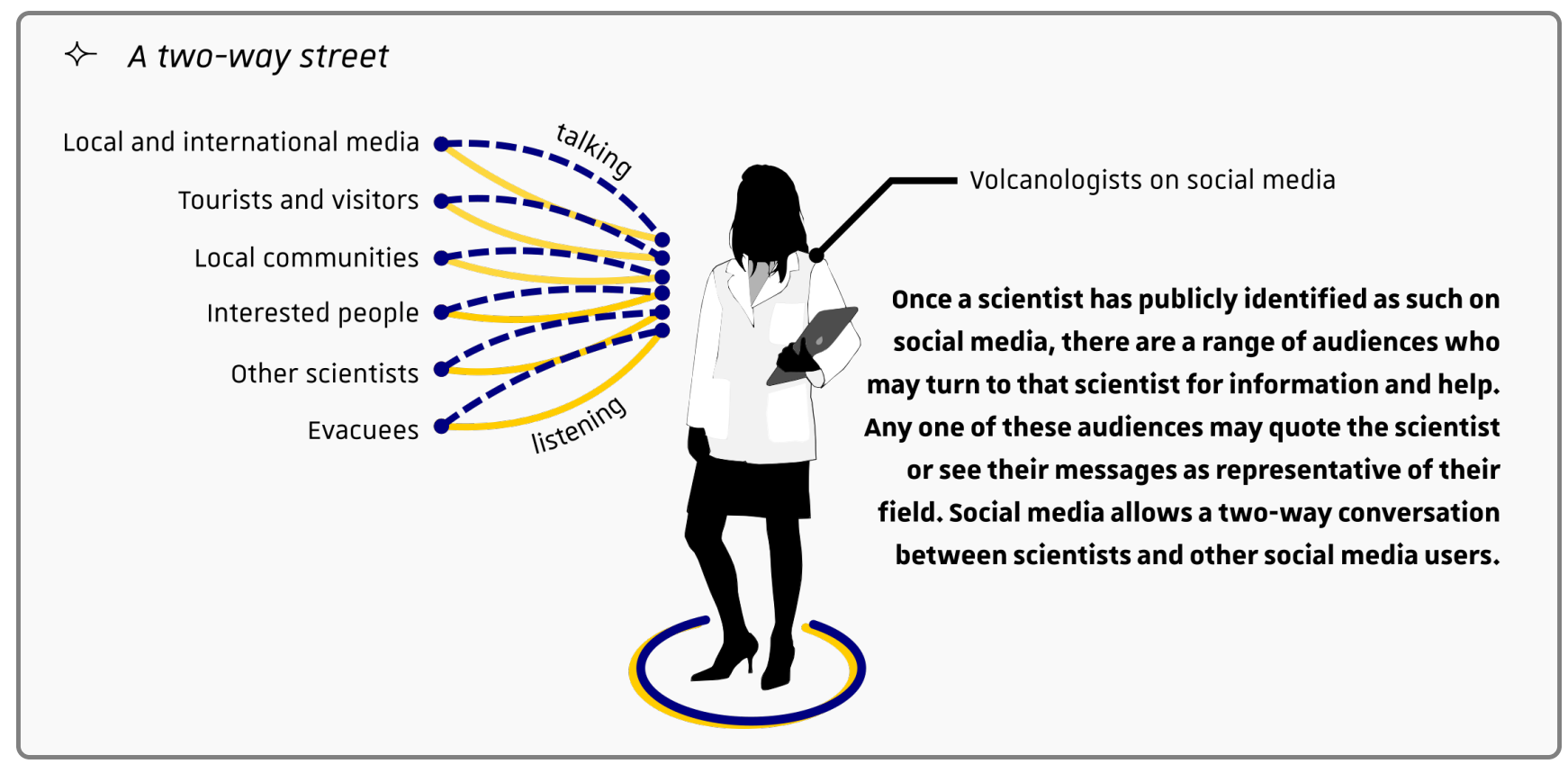

1985 at Nevado del Ruiz, Colombia authorities delayed action on warnings and an issued alert, and local populations underestimated the risk despite local education programmes resulting in the deaths of 23,000 people [Hall 1990; Voight 1990]. At best, effective communication can lead to a variety of successful outcomes such as successful evacuation and minimum fatalities as seen during eruptions such as Mt Pinatubo in 1991 [Newhall and Solidum 2017], Mt St Helens in 1980 [Tilling 2000], and Volcán Tungurahua in 2006 [Mothes et al. 2015].

In response to several volcanic crises in the Caribbean an operations manual for the Caribbean, Communication During Volcanic Emergencies [Solano 2003], was published by a DFID (UK's Department for International Development) funded consortium [McGuire et al. 2009]. Aimed at stakeholders, the manual details effective strategies for the management of a volcanic crisis at all levels. Of particular interest to practising volcanologists is the section on 'Scientists' and its examples of both effective and bad practice including issuing forecasts, talking to the media, reducing opportunities for dissemination of misinterpretation, the interaction between scientists and the role of visiting scientists. In 1999, Newhall and the Subcommittee for Crises Protocols published Professional conduct of scientists during volcanic crises - a publication from the International Association of Volcanology and Chemistry of the Earth's Interior (IAVCEI). In it, they discuss the issues and challenges that have arisen in past volcanic crises such as poor communication and teamwork among scientists, leadership problems, issues for visiting scientists (invited and uninvited), unwise and unwelcome warnings, poor communication between scientists and public officials, and finally ineffective relations with news media [Newhall et al. 1999]. They offer suggestions for best practice and a personal checklist for volcanologists to consider before acting in a volcanic crisis. Whilst providing excellent guidance both of these documents were written before the recent dramatic rise in social media and online news, both of which present new opportunities and challenges to managing a volcanic crisis.

\section{SOCIAL MEDIA DURING A CRISIS}

In 2008, a review of the (effective) crisis response by the United States Geological Survey (USGS) team at Mt St Helens during its 2004-06 reawakening noted that "In particular, today's widespread use of the Internet and the around-the-clock news cycle required a fast, sustained pace of information delivery that frequently pushed the limits of staffing and internal communications" [Driedger et al. 2008]. And this at a time when the popularity of online news and social media was only just beginning to grow. This pressure is now many times greater and there are examples of where social media has been used both effectively and poorly during a crisis.

In Indonesia, the National Disaster Management Agency (BNPB) uses Twitter to disseminate updates on ongoing disasters, such as the Mt Sinabung eruption in 2014, reaching local communities and providing information for the media. These tweets tend to follow a traditional top-down communication model [Chatfield et al. 2014]. However, the strength of social media can often be in the more community-led interactions. Community groups, such as on Facebook, can be effective at disseminating official information posted by the authorities and generating a local support network (e.g. during the 2010/11 Queensland and Victoria Floods; Bird et al. [2012]). Authorities can harness this network to help improve their disaster response. During 
the 2011 Spring Storm Season the American Red Cross used social media such as Facebook and Twitter to connect to people affected by the storms and understand their needs [American Red Cross 2011]. In 2012, the National Coordinating Commission for Disaster Reduction (CONRED) used social media to map the effects of the eruption of Santiaguito Volcano, Guatemala, to inform their relief response [Carranza-Tresoldi 2013].

However, there have been issues with amateur, or even fake, volcanologists doing their own interpretation of the data and spreading misinformation during a volcanic crisis. The Albay Disaster Risk Reduction and Management Council have battled against inaccurate advisories and analyses at Mayon Volcano, which have not been issued by Philippine Institute of Volcanology and Seismology (PHIVOLCS) but have nevertheless gained traction on social media and then have been picked up by news outlets [Recuenco 2018]. "Clickbait" headlines about impending volcanic doom are common in the online tabloid media and have the potential to spread anxiety and deflect attention from the real volcanic news. Looking at false news and how it spreads via Twitter, Vosoughi et al. [2018] showed how much further and faster lies travel compared to the truth on social media. Conflicting or incorrect information spread in this way, even by professional volcanologists speculating on images or data during a volcanic crisis, has the potential to be very disruptive towards crisis management, such as either causing unnecessary concern, or mistrust in the official authorities.

\section{OPPORTUNITIES AND CHALLENGES OF SOCIAL ME- DIA TO THE VOLCANO-COMMUNITY}

We summarise the opportunities and challenges that a volcano-community presence on social media brings to crisis management based on our experiences, discussions with colleagues and observations during recent events.

Opportunities include:

- Rapid, global dissemination of data, information and advice during a volcanic crisis;

- Use of a hashtag can enable public to access a variety of sources of data and information quickly;

- Public has direct access to scientists and authorities to ask questions, clarify and understand decision-making;

- Network of varied expertise across the globe;

- Ability for volcanologists with a social media presence to amplify and lead people to the official sources;

- Volcanologists and institutions/authorities can see rumours starting in real time and act to quash them;
- Instant feedback when information is misunderstood by public or media;

- Ability to share and amplify good volcanology research during quiescence to increase general understanding and trust in volcano-science;

- Datamine reactions and public comments for situational awareness during a crisis.

Challenges include:

- Misinformation can spread rapidly;

- Non-local scientists or amateurs posting their own interpretations and conflicting information can cause confusion during a volcanic crisis. How can we best support official agencies during a crisis?

- Speculation and scientists publicly questioning official decisions and statements can mix the message from observatories and DRR agencies;

- Flooding the hashtag with general interest posts can obscure and bury information which could be used by authorities to inform relief efforts or prevent the public accessing relevant information;

- "Disaster porn" and the ethics of sharing distressing images;

- Does the use of technical language by volcanologists clarify or obfuscate the message?

- Do click-bait stories of volcanic doom create a "cried wolf" culture?

- Explaining uncertainty while building trust in forecasts and recommendations;

- Working within existing agency guidelines and with inter-agency agreements;

- The resources (e.g. staff time) needed to effectively utilize social media for crisis communication will often be beyond the capacity of local agencies.

\section{FURTHER RESEARCH REQUIRED: A CALL}

Late 2017 through 2018 has seen several volcanic crises that have extensively used social media as part of the crisis communication with international interest (for example, the 2017 Mt Agung eruption, Indonesia; the 2018 Volcán de Fuego eruption, Guatemala; the 2018 Lower East Rift Zone (LERZ) eruption on Kīlauea, USA). Following this, the first "social media in volcanology" conference workshop (Social Media Utility in Volcano and Hazard Communication - Panel Discussion) and session (Leveraging the Power and Speed of Social Media to Expand Volcano Communication) were held at the 2018 Cities on Volcanoes 10 meeting in Naples. At the 


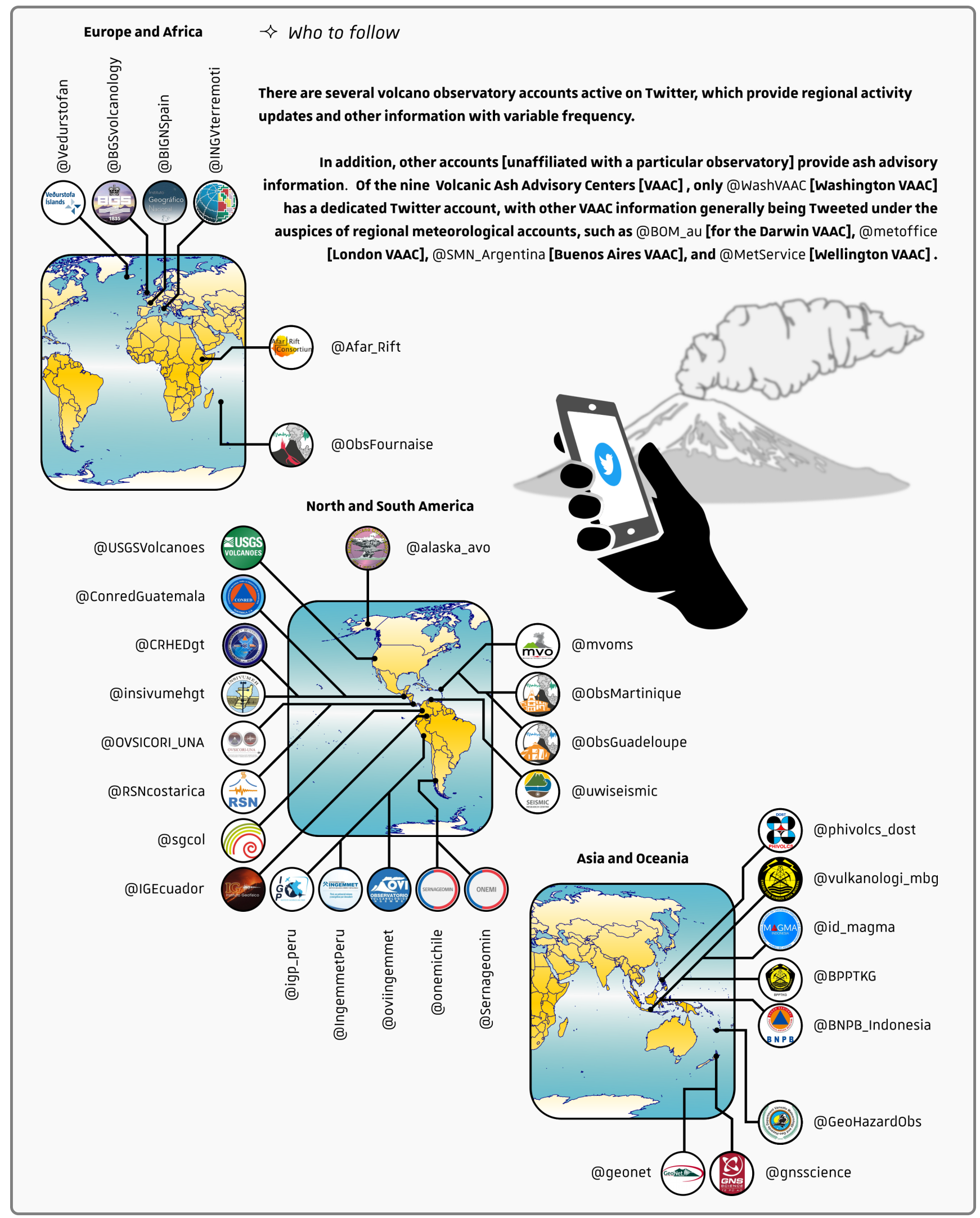

American Geophysical Union Fall Meeting in December 2018, the session The Hazards of Hazard Communication: Importance, Rewards, and Challenges of Science in the Public Sphere featured talks discussing social media, demonstrating the need and scope for research on this topic.

There is a wide variety of potential research on the use of social media in science communication, with par- 
ticular reference to volcanic crises. For example, anecdotal research by those involved in communication during a volcanic crisis can give important insights allowing others to learn from the experience. In the preface to the new book Observing the Volcano World: Volcano Crisis Communication, Fearnley makes the case for the importance of capturing this experience as published works [Fearnley et al. 2018]. We argue here that this should now include the experiences of those working in and around social media and working with social scientists to understand how to best utilise these tools. Analysis is required of who is using social media for information during a volcano crisis, whether the information is reaching local communities as intended, and whether it is in a form that is useful to them. How disruptive are alarmist media reports and conflicting interpretations by outside (or amateur) volcanologists? To what extent does terminology in a social media context matter during a crisis? How can the broader volcano community help and support local authorities during a volcanic eruption?

At Volcanica we welcome a wide variety of research articles in this field. Firstly, from volcanologists working in and around science communication, crisis management or with expertise or experience in social media. But also, from other disciplines such as those working in other hazards fields (e.g. meteorology), emergency managers and those working in disaster risk reduction who can contribute to the discussion in the volcano-community. This research should provide the evidence-base required to update the Professional conduct of scientists during volcanic crises for a social media context and ultimately improve communication during a crisis with the aim of reducing the impacts of volcanic eruptions.

Yours volcanically,

- Rebecca Williams and Janine Krippner

$$
\begin{aligned}
& \text { "What is interesting is the power and impact of } \\
& \text { social media ... So we must try to use social } \\
& \text { media in a good way." } \\
& \text { - Malala Yousafzai }
\end{aligned}
$$

\section{ACKNOWledgements}

We are indebted to the incredible community of scientists and practitioners on social media, particularly on Twitter. Our thanks go to the many colleagues who have spent countless hours sharing their knowledge and engaging in discussion with how best we as a community can interact on social media. We hope that we've best represented these discussions but any inaccuracies or omissions are our own. In particular, thanks to those involved in the Voices of Volcanology Project and folks who attended the recent meet-up at AGU. Thank you to Jamie Farquharson for the infographics and to Jamie and Fabian Wadsworth for comments on drafts of this piece.

\section{Affiliations}

Rebecca Williams: Rebecca.Williams@hull.ac.uk Department of Geography, Geology \& Environment; University of Hull, Hull HU6 7RX, UK

Janine Krippner: jkrippner@concord.edu Department of Physical Sciences, Concord University, 1000 Vermillion St. Athens, West Virginia 24712-1000, USA

\section{COPYRIGHT NOTICE}

(c) The Author(s) 2019. This article is distributed under the terms of the Creative Commons Attribution 4.0 International License, which permits unrestricted use, distribution, and reproduction in any medium, provided you give appropriate credit to the original author(s) and the source, provide a link to the Creative Commons license, and indicate if changes were made.

\section{REFERENCES}

American Red Cross (2011). Press Release: More Americans Using Social Media and Technology in Emergencies: New American Red Cross Survey Finds High Expectations on Response Organizations. URL: http : / / www . redcross . org / portal / site / en / \%20menuitem. 94aae335470e233f6cf911df43181aa0

?vgnextoid=7 (visited on 12/18/2018).

Bird, D., M. Ling, and K. Haynes (2012). "Flooding Facebook - the use of social media during the Queensland and Victorian floods." Australian Journal of Emergency Management 27.1, pp. 27-33.

Blakeslee, S. (2011). Wrong Once, Experts Keep Quiet On Volcanic Activity in California. urL: ht tps: / / www. nytimes . com/1990/09/11/science/wrong-onceexpert-keep-quiet-on-volcanic-activity-incalifornia.html.

Carranza-Tresoldi, J. A. (2013). Social Media Maps a Volcano's Aftermath: Tracking the Consequences of the Guatemalan Eruption. URL: https://www. esri.com/ esri - news / arcnews / spring13articles / social media - maps - a - volcanos - aftermath (visited on $12 / 18 / 2018)$.

Cashman, K. V. and S. J. Cronin (2008). "Welcoming a monster to the world: Myths, oral tradition, and modern societal response to volcanic disasters". Journal of Volcanology and Geothermal Research 176.3, pp. 407-418. Dor: 10.1016/ j . jvolgeores .2008.01. 040. 
Chatfield, A. T., C. G. Reddick, D. I. Inan, and U. Brajawidagda (2014). "E-government, social media, and risk perception communication at the edge of disaster". Proceedings of the 15th Annual International Conference on Digital Government Research - dg.o '14. New York: ACM Press. DoI: 10.1145/2612733.2612752.

Dörries, M. (2003). "Global science: the eruption of Krakatau”. Endeavour 27.3, pp. 113-116. DoI: 10 . 1016/s0160-9327 ( 03 ) 00107-8.

Driedger, C. L., C. A. Neal, T. H. Knappenberger, D. H. Needham, R. B. Harper, and W. P. Steele (2008). "Hazard information management during the autumn 2004 reawakening of Mount St. Helens volcano, Washington". A volcano rekindled: the renewed eruption of Mount St. Helens, 2004-2006. Ed. by D. R. Sherrod, W. E. Scott, and P. H. Stauffer. U.S. Geological Survey Professional Paper 1750, pp. 505-519. DoI: $10.3133 /$ pp 175024.

Fearnley, C. J., D. K. Bird, K. Haynes, W. J. McGuire, and G. Jolly, eds. (2018). Observing the Volcano World. Springer International Publishing. Dor: 10 . 1007 / 978-3-319-44097-2.

Fiske, R. S. (1984). "Volcanologists, journalists, and the concerned local public: a tale of two crises in the eastern Caribbean". Explosive Volcanism: Inception, Evolution, and Hazards. Ed. by National Research Council. Washington, DC: The National Academies Press. Chap. 13, pp. 170-176. Dor: https : // doi .org/10. $17226 / 18602$.

Hall, M. L. (1990). "Chronology of the principal scientific and governmental actions leading up to the November 13, 1985 eruption of Nevado del Ruiz, Colombia". Journal of Volcanology and Geothermal Research 42.1-2, pp. 101-115. DoI: 10 . $1016 / 0377$ 0273 ( 90 ) 90072-n.

Hill, D. P., M. T. Mangan, and S. R. McNutt (2017). "Volcanic Unrest and Hazard Communication in Long Valley Volcanic Region, California". Advances in Volcanology. Springer International Publishing, pp. 171187. DoI: 10.1007/11157_2016_32.

Kemp, S. (2018). Digital in 2018: World's internet users pass the 4 billion mark. URL: https: // wearesocial. com / uk / blog / 2018/01/global - digital - report2018 (visited on 01/04/2019).

McGuire, W., M. Solana, C. Kilburn, and D. Sanderson (2009). "Improving communication during volcanic crises on small, vulnerable islands". Journal of Volcanology and Geothermal Research 183.1-2, pp. 63-75. DoI: 10.1016/ j . jvolgeores.2009.02.019.

Mothes, P. A., H. A. Yepes, M. L. Hall, P. A. Ramón, A. L. Steele, and M. C. Ruiz (2015). "The scientific-community interface over the fifteen-year eruptive episode of Tungurahua Volcano, Ecuador". Journal of Applied Volcanology 4.1. Dor: 10.1186/s13617015-0025-y.

Newhall, C., S. Aramaki, F. Barberi, R. Blong, M. Calvache, J.-L. Cheminee, R. Punongbayan, C. Siebe, T.
Simkin, S. Sparks, and W. T. [ IAVCEI Subcommittee for Crisis Protocols] (1999). "Professional conduct of scientists during volcanic crises". Bulletin of Volcanology 60.5, pp. 323-334. Dor: 10.1007/pl00008908.

Newhall, C. and R. U. Solidum (2017). "Volcanic Hazard Communication at Pinatubo from 1991 to 2015". Advances in Volcanology. Springer International Publishing, pp. 189-203. Dor: 10.1007/11157_2016_43.

Nomade, S. et al. (2016). "A 36, 000-Year-Old Volcanic Eruption Depicted in the Chauvet-Pont d'Arc Cave (Ardèche, France)?" PLOS ONE 11.1, e0146621. Dor: 10.1371/ journal. pone.0146621.

Pyle, D. M. (2017). "Visions of Volcanoes". 19: Interdisciplinary Studies in the Long Nineteenth Century 2017.25. Dor: 10.16995/ntn.790.

Recuenco, A. (2018). Authorities waging war vs. fake volcanologists in social media.. URL: https: / / news . mb . com . ph / 2018 / 01 / 21 / authorities - waging - war vs-fake-volcanologists-in-social-media/ (visited on $01 / 21 / 2018)$.

Schmitt, A. K., M. Danišık, E. Aydar, E. Şen, İ. Ulusoy, and O. M. Lovera (2014). "Identifying the Volcanic Eruption Depicted in a Neolithic Painting at Çatalhöyük, Central Anatolia, Turkey". PLoS ONE 9.1, e84711. Dor: 10.1371/ journal . pone. 0084711.

Solano, M. C. (2003). Communications during volcanic emergencies. A handbook for the Caribbean. URL: http: / / www . benfieldhrc . org / disaster_studies / projects/Carib.2003.pdf (visited on 01/02/2019).

Statista (2018). Most famous social network sites 2018, by active users. URL: https : / / www . statista . com / statistics / 272014 / global - social - networks ranked - by - number - of - users/ (visited on 01/02/2019).

Stone, J., J. Barclay, P. Simmons, P. D. Cole, S. C. Loughlin, P. Ramón, and P. Mothes (2014). "Risk reduction through community-based monitoring: the vigias of Tungurahua, Ecuador". Journal of Applied Volcanology 3.1. DoI: 10.1186/s13617-014-0011-9.

Stothers, R. B. and M. R. Rampino (1983). "Volcanic eruptions in the Mediterranean before A.D. 630 from written and archaeological sources". Journal of Geophysical Research 88.B8, p. 6357. DOI: 10 . 1029 / jb088ib08p06357.

Sullivan, F. A. (1968). "Pliny Epistulae 6. 16 and 20 and Modern Volcanology". Classical Philology 63.3, pp. 196-200. DoI: 10.1086/365375.

Swanson, D. A. (2008). "Hawaiian oral tradition describes 400 years of volcanic activity at Kilauea". Journal of Volcanology and Geothermal Research 176.3, pp. 427-431. Dor: 10.1016/ j . jvolgeores.2008.01. 033.

Taylor, P. W. (1995). "Myths, legends and volcanic activity: an example from northern Tonga". The Journal of the Polynesian Society 104.3, pp. 323-346.

Tilling, R. I. (2000). Mount St. Helens 20 years later: what we've learned. URL: http : / / www . geotimes org / may00/featurestory.html (visited on 01/02/2019). 
Tobin, G. A. and L. M. Whiteford (2002). "Community Resilience and Volcano Hazard: The Eruption of Tungurahua and Evacuation of the Faldas in Ecuador". Disasters 26.1, pp. 28-48. DoI: 10.1111/1467-7717. 00189.

Voight, B. (1990). "The 1985 Nevado del Ruiz volcano catastrophe: anatomy and retrospection". Journal of Volcanology and Geothermal Research 44.3-4, pp. 349386. DoI: 10 .1016/0377-0273 ( 90 )90027-d.
Vosoughi, S., D. Roy, and S. Aral (2018). "The spread of true and false news online". Science 359.6380, pp. 1146-1151. Dor: 10.1126/science. aap9559.

York Museums and Gallery Trust (2017). Tempest Anderson - Explorer and Surgeon. URL: https : / / www . yorkshiremuseum . org . uk / collections / collections - highlights / temptest - anderson explorer-and-surgeon/ (visited on 01/02/2019). 